\title{
PRIMEIRO ISOLAMENTO DE LENTIVÍRUS DE PEQUENOS RUMINANTES EM CAPRINO NATURALMENTE INFECTADO EM REBANHO DO RIO GRANDE DO NORTE, BRASIL
}

\author{
A.L.V.L. Feitosa ${ }^{1}$, M.F.S. Teixeira ${ }^{1}$, R.R. Pinheiro ${ }^{2}$, A.A. Pinheiro ${ }^{2}$, D.A.A. de Azevedo $^{3 *}$, S.M. Alves ${ }^{3 *}$ \\ ${ }^{1}$ Universidade Estadual do Ceará, Faculdade de Veterinária, Laboratório de Virologia, Av. Paranjana 1700, \\ CEP 60740-093, Fortaleza, CE, Brasil. E-mail: aryanalima@yahoo.com.br
}

\author{
RESUMO
}

\begin{abstract}
O Vírus da Artrite Encefalite Caprina (CAEV) e Vírus Maedi-visna (MVV) pertencem ao gênero Lentivírus da família Retroviridae. São considerados geneticamente distintos, mas antigenicamente relacionados. O objetivo desde trabalho foi isolar o vírus da CAE de um animal oriundo de um rebanho do Rio Grande do Norte e positivo pelo teste de Imunodifusão em Gel de Agarose (IDGA) através do co-cultivo de leucócitos infectados do sangue periférico em Membrana Sinovial Caprina (MSC). Dezesseis caprinos da raça Saanen, com suspeitas clínicas para CAE foi testado por IDGA e Western Blotting. Para o isolamento viral, os leucócitos do sangue periférico foram isolados por co-cultivo em MSC. Monócitos/Macrófagos coletados foram inoculados em monocamadas pré-formadas em garrafas A25. O resultado do IDGA foi positivo para um animal, confirmado por Western Blotting. Após 50 dias de co-cultivo, foi realizada a coloração da monocamada com cristal de violeta a $0,1 \%$ para visualização do ECP e realizada nested-PCR do sobrenadante do cocultivo, com confirmação do efeito citopático viral. A cepa isolada, denominada BrRN-CNPC.G1 foi considerada o primeiro isolamento do CAEV no Estado do Rio Grande do Norte. Esse estudo permitirá em breve, realizar a caracterização molecular do genoma do vírus isolado, através da análise de seus diferentes genes estruturais e comparar com outras sequencias virais isoladas para identificar a provável origem da infecção desse animal e estabelecer as possíveis divergências entre cepas padrões de Lentivírus e cepas regionais circulantes.
\end{abstract}

PALAVRAS-CHAVE: Co-cultivo, membrana sinovial caprina, CAEV.

\section{ABSTRACT}

FIRST ISOLATION OFSMALL RUMINANT LENTIVIRUSFROM A NATURALLY INFECTED GOAT IN A FLOCK IN THE STATE OF RIO GRANDE DO NORTE, BRAZIL. Caprine Arthritis Encephalitis virus (CAEV) and Visna/maedi virus (VISNA), belong to the genus Lentivirus family Retroviridae. The aim of the present study was to isolate the CAE virus from a positive goat when tested by agarose gel immunodifusion (AGID) by cocultivation techniques of infected peripheral blood leukocytes in goat synovial membrane (GSM). In this study, one flock of 16 goats, obtained from a flock of Rio Grande do Norte, Brazil, with clinical suspicions for CAEV, was screened using agar-gel immunodiffusion (agid) and Western blotting. The result was positive for one animal, confirmed by Western blotting. For virus isolation, peripheral blood leukocytes (PBL) were isolated from the blood for co-culture on goat sinovial membrane (GSM) cells. Monocytes / macrophages collected were inoculated in a monolayer of 90\% semiconfluent cells in the A25 culture bottles. After 50 days of co-culture, the monolayer was stained with crystal violet $0.1 \%$ for viewing viral cytopathic effects (CPE) characteristic of viruses, and nested-PCR was performed with the supernatant of co-culture for confirmation of CPE. The isolate, named BrRN-CNPC.G1, was considered the first isolation of small ruminant lentivirus from a naturally infected goat in a flock in Rio Grande do Norte, Brazil. This study will soon allow for the molecular characterization of the isolated virus genome, by analysis of its different structural genes and their comparison with other isolated viral sequences to identify the likely source of infection of that animal and establish the possible differences between strains of lentiviruses and circulating regional strains.

KEY WORDS: Co-culture, goat sinovial membrane, CAEV.

${ }^{2}$ Embrapa Caprinos e Ovinos, Laboratório de Virologia, Sobral, CE, Brasil.

${ }^{3}$ Universidade Estadual Vale do Acaraú, Sobral, CE, Brasil.

*Iniciação Científica CNPq/PIBIC e FUNCAP. 
Os Lentivírus de Pequenos Ruminantes (LVPRs) estão amplamente distribuídos entre caprinos e ovinos. Diferentes formas clínicas da doença foram descritas em pequenos ruminantes infectados como vírus, tais como artrite progressiva crônica, pneumonia e mastite em animais adultos e, mais raramente, leucoencefalomielite em animais de dois a quatro anos de idade (CRAWFORD; ADAMS, 1981). O Vírus da Artrite Encefalite Caprina (CAEV) e Vírus Maedi-visna (VISNA) pertencem ao gênero Lentivírus da família Retroviridae. São considerados geneticamente distintos, mas antigenicamente relacionados. De acordo com a nova nomenclatura, os LVPRs são classificados em cinco grupos: A-D proposto por SHAH et al. (2004) e o grupo E, altamente divergente, proposto por ReINA et al. (2009). Segundo Correlet al. (1992), CAEV possui tropismo por células do sistema imune da linhagem dos monócitos/macrófagos, na qual incorpora seu genoma, escapando dos mecanismos de defesa do hospedeiro.

No Brasil, por meio de isolamento em células infectadas de ovinos soropositivos, que foram submetidas à microscopia eletrônica, foi concluído o primeiro isolamento deste vírus no país (Moojen, et al., 1986) nos Estados do Rio Grande do Sul, Rio de Janeiro, em Minas Gerais, por Abreu et al. (1998) em Pernambuco, Tigre et al. (2006) na Bahia e por Feitosa et al. (2010) no Estado do Ceará. O isolamento de cepas regionais contribui para um melhor conhecimento da diversidade genética circulantes desses vírus e pode ainda contribuir para melhorar o controle da doença. O objetivo desde trabalho foi isolar o vírus da CAE de um animal oriundo de um rebanho do Rio Grande do Norte e positivo pelo teste de Imunodifusão em Gel de Agarose (IDGA) através do co-cultivo de leucócitos infectados do sangue periférico em Membrana Sinovial Caprina (MSC).

Dezesseis caprinos da raça Saanen, obtido de um rebanho do Rio Grande do Norte com suspeitas clínicas para CAE foi testado sorologicamente para a presença de anticorpos contra a proteína Gag do capsídeo (p28) usando o kit IDGA produzido pela Embrapa Caprinos eOvinos, este sendo previamente testado contra o controle positivo do kit Americano (Caprine Arthritis-Encephalitis/Ovine Progressive Pneumonia Antibody Test Kit. Veterinary Diagnostic Technology,Inc ${ }^{\circledR}$ - USA). O rebanho foi posteriormente testado para a CAE por Western Blotting, segundo a metodologia descrita por PINHEIRO (2001).

Foram coletados $10 \mathrm{ml}$ de sangue por venipuntura da jugular em tubo com anticoagulante (EDTA) para obtenção dos leucócitos do sangue periférico. Estes foram isolados por centrifugação a $380 \mathrm{~g}$ por 10 minutos. Os eritrócitos foram hemolisados com 8 $\mathrm{ml}$ de cloreto de amônio $(0,84 \%)$, por duas vezes. O pellet foi lavado em $10 \mathrm{ml}$ de solução salina fosfato
PBS a $380 \mathrm{~g}$ por 5 min e finalmente ressuspendido em $1 \mathrm{~mL}$ de PBS para uso no co-cultivo em células MSC.

Explantes das membranas sinoviais caprinas das articulações intercarpais de membros anteriores de cabritos livres de CAEV foram cultivados em Meio Essencial Mínimo (MEM-G), acrescido de $10 \%$ de Soro Fetal Bovino (SFB), incubadas a $37^{\circ} \mathrm{C}$ em atmosfera de $5 \%$ de $\mathrm{CO}_{2}$ (ABREu et al., 1998) em garrafas de cultura celular A25. O meio foi trocado até a monocamada obter $90 \%$ de confluência.

Monócitos/Macrófagos ( $200 \mathrm{~mL}$ ) coletados foram inoculados em monocamadas pré-formadas em garrafas A25 (capacidade $25 \mathrm{~cm}^{2}$ ) eincubados durante 60 minutos em estufa $37^{\circ} \mathrm{C}$ a $5 \%$ de $\mathrm{CO}_{2}$ acrescidos de 1 $\mathrm{ml}$ de meio essencial mínimo (MEM) sem soro fetal bovino (SFB) (Sigma ${ }^{\circledR} ; \mathrm{BDV}$ Free). Após o período de incubação foram adicionados 3,5 $\mathrm{ml}$ de MEM com $10 \%$ de soro fetal bovino. O meio foi trocado a cada sete dias e a passagem foi realizada a cada 21 dias, com adição de $200 \mathrm{~mL}$ de células da MSC a cada troca de meio ou passagem. A monocamada foi examinada diariamente em microscópio invertido para verificação de efeito citopático viral (ECP), formação de sincícios, fusão nuclear ou vacuolização. Após 50 dias de co-cultivo, foi realizada a coloração da monocamada com cristal de violeta a $0,1 \%$ para visualização do ECP.

Osobrenadante de co-cultivo coletado a cada sete dias foi utilizado para extração do DNA proviral. Uma proporção de 1:1 de PBS 1X foi utilizada para centrifugar $5 \mathrm{ml}$ de sobrenadante de co-cultivo a 250 g por 5 minutos. Após a centrifugação a fase superior foi descartada e o pellet novamente lavado em PBS nas mesmas condições anteriores. Em seguida o pellet foi ressuspendido em $2 \mathrm{ml}$ de tampão hipertônico, durante 2 minutos a temperatura ambiente, para lise do citoplasma celular, seguido de centrifugação a $1.100 \mathrm{~g}$ por 10 minutos. O pellet foi ressuspendido em $2 \mathrm{~mL}$ de PBS e submetido a centrifugação a $1100 \mathrm{~g}$ por 10 minutos. Por fim, o sedimento foi novamente ressuspendido em $250 \mathrm{~mL}$ de tampão de PCR e homogeneizado. O material foi, então, tratado com proteinase $\mathrm{K}(0,1 \mathrm{mg} / \mathrm{mL})$, durante 60 minutos, em banho-maria a $56^{\circ} \mathrm{C}$. A proteinase $\mathrm{K}$ foi inativada termicamente em água fervente a $100^{\circ} \mathrm{C}$ por 10 minutos e acondicionadas em freezer a $-20^{\circ}$ C até a sua utilização.

Dois rounds de PCR (nested-PCR) foram realizados para amplificar um fragmento de $187 \mathrm{pb}$ de DNA proviral, correspondente ao gene gag de CAEV. Todos os primers foram desenhados baseados na sequencia padrão de CAEV-Cork publicadas por SALTARELli et al. (1990). Foram utilizados dois pares de primers. Os oligonucleotídeos externos GEX5 (5'-CAAGCAGCAGGAGGGAGAAGCTG-3') e GEX3 (5'-TCCTACCCCCATAATTTGATCCAC-3') foram utilizados na primeira amplificação, cor- 
respondendo as bases 953-975 e o complemento 1249-1226, respectivamente. Os oligonucleotídeos internos GIN5 (5'-GTTCCAGCAACTGCAAACAGTAGCAATG-3') e GIN3 (5'-ACCTTTCTGCTTCTTCATTTAATTTCCC- 3') foram usados na segunda amplificação, correspondendo as bases 997-1024 e o complemento 1181-1154, respectivamente. Para cada round de amplificação, foi utilizado um controle positivo referente ao CAEV-Cork e um controle negativo sem amostra de DNA em paralelo com todas as amostras. O mix de PCR constituiu de 34,6 mL de água sem DNA, $5 \mathrm{~mL}$ de tampão sem $\mathrm{MgCl}_{2}$ (Tris $\mathrm{HCl} 10 \mathrm{mM}, \mathrm{KCl} 50 \mathrm{mM}$ ) 3,5 mL de $\mathrm{MgCl}_{2}(1,5 \mathrm{mM}), 1 \mathrm{~mL}$ de cada dNTPs $(100 \mathrm{mM})$ (Invitrogen $\left.{ }^{\circledR}\right), 2 \mathrm{~mL}$ de capa primers (20 pmol), 0,4 $\mathrm{mL}$ de Taq (2U) e $5 \mathrm{~mL}$ de amostra de DNA, tanto para o primeiro como para o segundo round. As amplificações foram realizadas usando termociclador da BioRad em 35 ciclos sob as seguintes condições: desnaturação a $94^{\circ} \mathrm{C}$ por 5 minutos, 1 minuto a $94^{\circ}$ C, anelamento a $56^{\circ} \mathrm{C}$ por um minuto e extensão a $72^{\circ} \mathrm{C}$ por 45 segundos, com extensão final por 7 minutos $72^{\circ} \mathrm{C}$ no último ciclo. Os produtos obtidos foram analisados por eletroforese em gel de agarose a $1 \%$, corado com brometo de etídio e visualizados em foto documentador de luz ultravioleta com densidade ótica de $260 \mathrm{~nm}$.

Um caprino naturalmente infectado foi detectado do teste de IDGA e confirmado por Western Blotting.

A garrafa de cultura celular foi corada no dia 50. O co-cultivo de Monócito/Macrófagos com MSC apresentou formação de poucos sincícios na monocamada, a partir do $27^{\circ}$ dia de co-cultivo, por observação em microscópio invertido. A cepa isolada, denominada BrRN-CNPC.G1 apresentou fenotipagem altamente lítica, causando a destruição quase total da monocamada desde os primeiros dias até o final do co-cultivo sendo necessário a adição de mais células a garrafa A25. A presença do efeito citopático viral na monocamada de MSC foi observada, com células gigantes, multinucleadas, variando de 4 a 8 núcleos por célula, confirmando assim, a presença do vírus em células do sistema monocítico fagocitário (SMF) (Fig.1).

A confirmação do isolamento foi feita pela amplificação do DNA proviral de CAEV, através de nested-PCR que detectou a presença fragmento de 187 bp do gene gag no sobrenadante de cultivo celular em todas as 6 coletas de sobrenadante do co-cultivo.
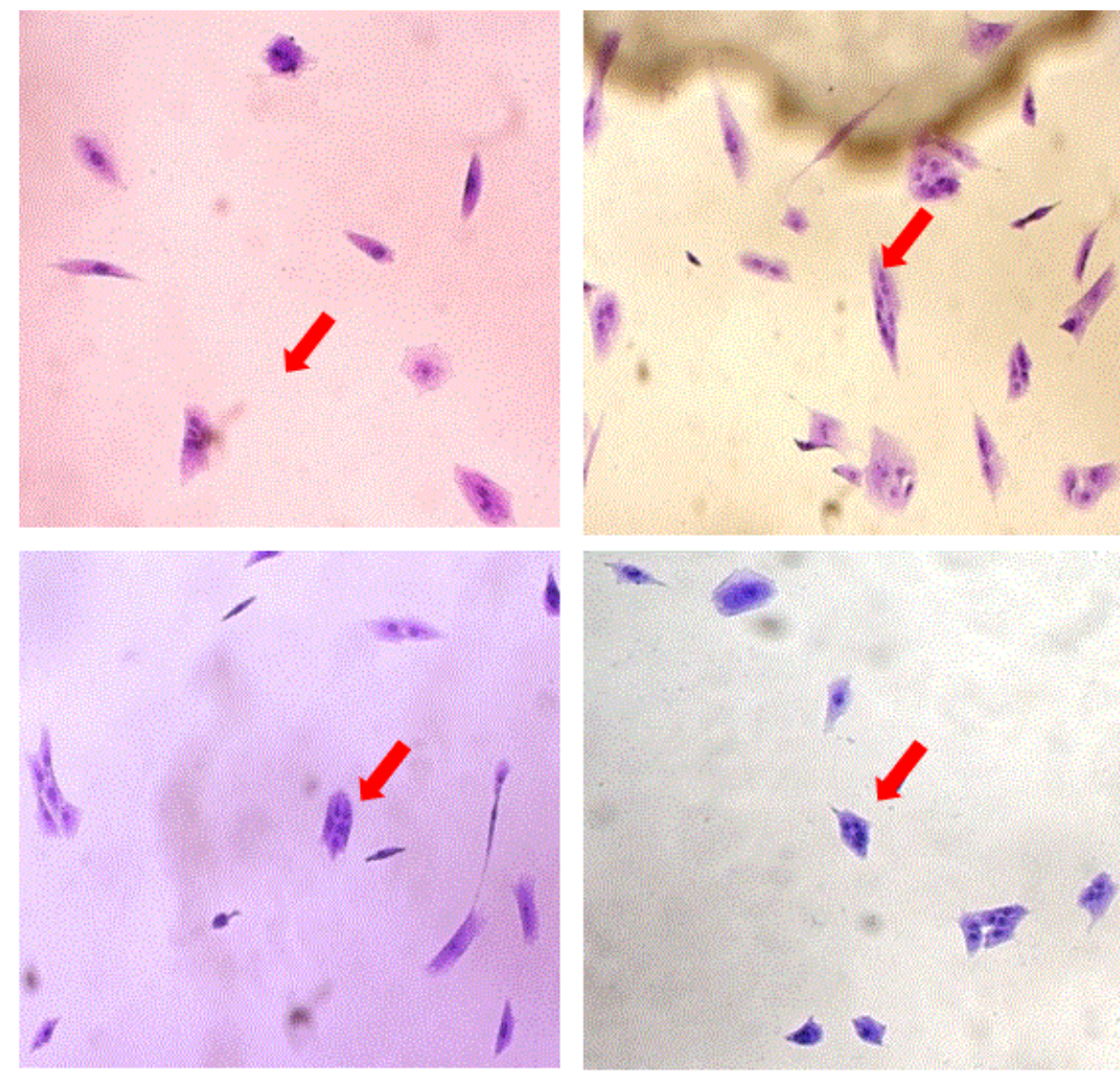

Fig. 1 - Isolamento a partir de co-cultivo de monócitos/macrófagos em MCS apresentando efeito citopático característico do CAEV com presença de células gigantes multinucleadas. 
A partir de um caprino da raça Saanen, foi isolada uma cepa de LVPR, denominada BrRB-CNPC.G1. Através da técnica de PCR, foram confirmadas a presença do DNA proviral no sobrenadante do co-cultivo. Os achados desse isolamento viral foram compatíveis com outros relacionados a amostras líticas de LVPR. Os Vírus da Artrite Encefalite Caprina (CAEV) e os Vírus Maedi-visna (VISNA) têm sido considerados como patógenos geneticamente distintos, mas antigenicamente relacionados entre si. Estes vírus estãoconstantes efacilmente transpondoa barreira entre espécies de caprinos e ovinos (VALAset al., 2000; KARR et al., 1996; SHAH et al., 2004). Os LVPRs estão classificados dentro de cinco grupos relativamente equidistante, denominados de A-E (SHAH et al., 2004; REINA et al., 2009). A alta heterogeneidade de sequências de nucleotídeos e aminoácidos em lentivírus pode determinar a sua antigenicidade, virulência ecrescimento e pode afetar sua persistência e o seu mecanismo de evasão. Apesar das diferenças no tropismo celular, órgãos alvo e patogenicidade, comumente encontrados entre CAEV e MVV, ambos os vírus foram recentemente atribuído a um único grupo, os LVPRs. A introdução de novas cepas merece atenção especial, pois podem se apresentar mais virulentas que as nativas, além do que muitos agentes como os vírus de RNA, que não apresentam a função de leitura e correção genética, podem ter altas taxas de mutação, de aproximadamente um milhão de vezes mais que a de animais e plantas. Consequentemente há uma enorme diversidade de populações de vírus de RNA que podem se tornar mais patogênicos e causarem novas doenças quando recém-introduzidos em ambientes (ANDRIOLI, 2001). Somente um pequeno número de LVPRs foi isolado no Brasil. Até agora foi concluído o isolamento deste vírus no país nos Estados do Rio Grande do Sul, Rio de Janeiro, Minas Gerais, Pernambuco, Bahia e no Ceará. Oisolamento de cepas regionais contribui para um melhor conhecimento da diversidade genética desses vírus (Feitosa et al., 2010). O conhecimento da variabilidadegenética pode ajudar a entender melhor os mecanismos de evolução molecular e heterogeneidade epidemiológica da infecção. A variabilidade genotípica e fenotípica das cepas circulantes pode ser útil para melhorar as ferramentas de diagnóstico, importantes para o controle e erradicação da doença. Futuros estudos de caracterização molecular das amostras virais isoladas poderão ajudar a desenvolver testes de diagnósticos mais sensíveis. Esse trabalho permitirá em breve, estudar a caracterização molecular do genoma do vírus isolado, através da análise de seus diferentes genes estruturais, tais como gag, env e pol e comparar com outras sequencias virais isoladas para identificar a provável origem dainfecção desse animal e estabelecer as possíveis divergências entre cepas padrões de Lentivírus e cepas regionais circulantes.
Foi realizado o primeiro isolamento do CAEV no Estado do Rio Grande do Norte a partir de monócitos/macrófagos co-cultivados em monocamadas de membrana sinovial caprina.

Este experimento foi realizado conforme os princípios éticos da experimentação animal estabelecidos pelo Comitê de Ética de Uso de Animais da Universidade Estadual do Vale do Acaraú (nº 001.02.2011).

\section{AGRADECIMENTOS}

UECE, EMBRAPA Caprinos e Ovinos, FUNCAP, $\mathrm{CNPq}$ e Banco do Nordeste pelo apoio financeiro para realização deste projeto.

\section{REFERÊNCIAS}

ABREU, S.R.O.; CASTRO, R.S.; NASCIMENTO, S.A. Produção de antígeno nucleoprotéico dos vírus da artrite encefalite caprina e comparação com os vírus Maedivisna para imunodifusão em ágar-gel. Pesquisa Veterinária Brasileira, v.18, p.57-60, 1998.

ANDRIOLI, A. Virus da artrite encefalite caprina: PCR e Isolamento Viral em amostras de sêmen, fluido uterino e embriões. 2001. Tese (Doutorado) - Escola de Veterinária, Universidade Federal de Minas Gerais, Belo Horizonte, 2001.

CORREL, M.D.; BRANDON, M.R.; SHEFFER D.; ADAMS, R.J.; NARAYAN, O. Ovine lentivirus is macrophagetropic and does not replicate productively in Tlymphocytes. Journal of Virology, v.66, p.2679-2688, 1992.

CRAWFORD, T.B.; ADAMS, D.S. Caprine arthritis-encephalitis: clinical features and presence of antibody in selected populations. Journal of the American Veterinary Medical Association, v.178, 713-719, 1981.

FEITOSA, A.L.V.L.; TEIXEIRA, M.F.S.; PINHEIRO, R.R.; CUNHA, R.M.S. da; LIMA, J.P.M.S.; ANDRIOLO, A.; DANTAS, T.V.M.; MELO, V.S.P. de; PINHEIRO, D.C.S. Phylogenetic analysis of small ruminant lentiviruses from Northern Brazil. Small Ruminant Research, v.94, n.1/3, p.205-209, 2010.

KARR, B.M.; CHEBLOUNE, Y.; LEUNG, K.; NARAYAN, $O$. Genetic characterization of two phenotipically distinct North American ovine lentiviruses and their possible origin from caprine arthritisencephalitis virus. Virology, v.225, n.1, p.1-10, 1996.

MOOJEN, V.; SOARES, H.C.; RAVAZZOLO, A.P.; PIZZOL, M.; GOMES, M. Evidência de infecção pelo lentivirus (Maedi-visna/artrite encefalite caprina) em caprinos no Rio Grande do Sul, Brasil. Arquivos da Faculdade de Veterinária, UFRGS, v. 14, p.77-78, 1986. 
PINHEIRO, R.R. Vírus da artrite encefalite caprina: desenvolvimento e padronização de ensaios imunoenzimáticos (ELISA e Dot-Blot) e estudo epidemiológico no Estado do Ceará. 2001. 115p. Tese (Doutorado) - Escola de Veterinária, Universidade Federal de Minas Gerais, Belo Horizonte, 2001.

REINA, R.; GREGO, E.; PROFITI, M.; GLARIA, I.; ROBINO, P.; QUASSO, A.; AMORENA, B.; ROSATI, S. Development of specific diagnostic test for small ruminant lentivirus genotype E. Veterinary Microbiology, v.138, p.251-257, 2009.

SALTARELLI, M.; QUERAT, G.; KONINGS, D.A.; VIGNE, R.; CLEMENTS, J.E. Nucleotide sequence and transcriptional analysis of molecular clones of CAEV which generate infectious virus. Virology, v.179, p.347-364, 1990.

SHAH, C.; BONI, J.; HUDER, J.B.; VOGT, H.R.; MUHLHERR, J.; ZANONI, R.; MISEREZ, R.;
LUTZ, H.; SCHUPBACH, J. Phylogenetic analysis and reclassification of caprine and ovine lentiviruses based on 104 new isolates: evidence for regular sheep-to-goat transmission and worldwide propagation through livestock trade. Virology, v.319, n.1, p.12-26, 2004.

TIGRE, D.M.; CAMPOS, G.S.; SILVIA, I.S. Isolamento e identificação do vírus da Artrite encefalite caprina, a partir do co-cultivo de células mononucleares do sangue com células de membrana sinovial de cabra. Revista de Ciência Médicas e Biológicas, v.5, n.2, p.124-131, 2006.

VALAS, S.; BENOIT, C.; BAUDRY, C.; PERRIN, G.; MAMOUN, R.Z. Variability and immunogenicity of caprine arthritis-encephalitis virus surface glycoprotein. Journal of Virology, v.74, n.13, p.6178-6185, 2000.

Recebido em 21/9/10

Aceito em 25/10/11 